\title{
A pessoa com deficiência no curso da história: aspectos sociais, culturais e políticos
}

\section{The disabled person in the course of history: social, cultural and political aspects}

\author{
Ronaldo Rodrigues Moises \\ Orcid: https://orcid.org/0000-0001-6845-9473 \\ Universidade Estadual de Mato Grosso do Sul, Campo Grande, Brasil, \\ professorronaldoef@gmail.com \\ Daniel Stockmann \\ Orcid: https://orcid.org/0000-0002-0623-8779 \\ Universidade Federal de Mato Grosso do Sul, Campo Grande, Brasil, \\ danielstk@hotmail.com
}

Received on 10/05/2020 - Approved on 20/05/2020

\section{Resumo}

Este artigo investiga concepções e tratativas sobre as pessoas com deficiência, em um recorte temporal iniciado com os primeiros registros históricos mundiais sobre essa temática até a retomada da democracia brasileira em 1985. Trata-se de uma revisão bibliográfica com perspectiva de análise crítica, realizada por meio de obras que investigam a história da pessoa com deficiência, da educação especial e da educação, de forma geral. Os resultados demonstraram que a história da pessoa com deficiência foi fruto de suas condições materiais de existência tendo, todavia, uma temporalidade paralela quando comparada às pessoas consideradas "normais", no que concerne à oferta de atendimentos e práticas formativas. Conclui-se que à pessoa com deficiência foi imposto, primariamente, provar-se (que tal, afirmar-se como ser) humano para poder viver e desfrutar das riquezas socialmente produzidas.

Palavras-chave: Conceito de Deficiência. Educação. História. 


\begin{abstract}
This article investigates conceptions and approaches about people with disabilities in a time frame started with the first world historical records about people with disabilities until the resumption of Brazilian democracy in 1985. This is a bibliographic review with a perspective of critical analysis carried out through of works that investigate the history of people with disabilities, special education and education. The results showed that the history of the person with a disability was the result of their material conditions of existence, having, however, a parallel temporality when compared to people considered normal with regard to the provision of care and training practices. It is concluded that the person with a disability was imposed, primarily, to prove himself human in order to be able to live and enjoy the socially produced wealth.
\end{abstract}

Keywords: Disability Concept. Education. Story.

\title{
Introdução
}

De origem latina, o termo "conceito" denota representação ou compreensão sobre algo, na condição de conhecimento socialmente construído e dentro de determinado período histórico (Weiszflog, 2020). Os conceitos, todavia, estão sujeitos às dinâmicas sociais, sofrendo, dessa forma, superações em virtude das transformações humanas.

Com relação à compreensão sobre as pessoas com deficiência e sua presença em diferentes civilizações, conforme Silva (1987), elas vivenciaram, historicamente, condições conceituais e de tratativas pendulares compreendidas, ora como resultantes de uma maldição, ora como algo divino, provenientes de uma força superior, porém, sempre pautadas no estereótipo do diferente.

Nos primórdios civilizatórios, em que os humanos ainda dependiam exclusivamente da caça e coleta, o abandono ou extermínio eram comuns, uma vez que:

$\mathrm{Na}$ existência de fator que poderia pôr fim ou causar grave prejuízo à totalidade do grupo ou tribo (por exemplo, uma pessoa enferma, seja por acometimento de doenças, seja por ferimentos em virtude de caça ou guerra), o mesmo deveria ser abandonado ou sacrificado em benefício da manutenção do coletivo (Moises, 2019, p. 40).

Posteriormente, o desenvolvimento da agricultura e de meios de produção capazes de gerar excedentes, permitiu condições de avanço para a humanidade. Com o advento do capitalismo industrial durante o século XVIII, surgem também movimentos sociais de reivindicações pró-classe trabalhadora contemplando, a reboque, minorias vinculadas, dentre essas as pessoas com deficiênciaii.

Atualmente, no escopo de leis educacionais, pessoas com deficiência são contempladas dentro do entendimento da Educação Especial, que assim define seu público-alvo: 
I - Alunos com deficiência: aqueles que têm impedimentos de longo prazo de natureza física, intelectual, mental ou sensorial.

II - Alunos com transtornos globais do desenvolvimento: aqueles que apresentam um quadro de alterações no desenvolvimento neuropsicomotor, comprometimento nas relações sociais, na comunicação ou estereotipias motoras. Incluem-se nessa definição alunos com autismo clássico, síndrome de Asperger, síndrome de Rett, transtorno desintegrativo da infância (psicoses) e transtornos invasivos sem outra especificação.

III - Alunos com altas habilidades/superdotação: aqueles que apresentam um potencial elevado e grande envolvimento com as áreas do conhecimento humano, isoladas ou combinadas: intelectual, liderança, psicomotora, artes e criatividade (Brasil, 2009, p. 17).

Fruto de distintas compreensões, a rigor, ponderadas pelos prismas das condições de subsistência, do misticismo, da política e, posteriormente da ciência e da educação, o tempo histórico da humanidade relegou majoritariamente às pessoas com deficiência a marginalização e o não protagonismo, como se observará neste trabalho.

\section{Macroperíodos e a pessoa com deficiência}

À luz do materialismo histórico, ao pesquisador é imposto não se furtar a considerar como matriz fundante as condições materiais de existência nas quais determinado fenômeno é gerado. De igual modo, o entendimento sobre conceito não deve concentrar suas atenções exclusivamente no produto ou palavra, mas no processo social de sua elaboração uma vez que, "(...) a palavra é o microcosmo da consciência" (Vigotski,1998), logo, consequência e fruto da materialidade histórica.

Dessa forma, antes de se julgar ou sentenciar o comportamento de determinadas culturas e suas civilizações, é preciso contemplá-lo e indagá-lo em sua dinâmica social vivida, pois:

\footnotetext{
Se nada ganhamos com os conceitos de verdade e erro, menos ainda alcançamos com os do bem e do mal. Esta antítese movese, pura e exclusivamente, dentro da órbita moral, isto é, num terreno que pertence à história humana, onde já sabemos que pouquíssimas verdades definitivas e inapeláveis podem fecundar. As ideias do bem e do mal variaram tanto de povo para povo, de geração para geração, que, não poucas vezes, chegam a se contradizer abertamente (Engels, 1979, p. 78).
}

Neste sentido, partindo da compreensão do sujeito como produto de seu tempo, verifica-se que, passado o período da pré-história da humanidade, cuja ausência de registros, no tocante às pessoas com deficiência, é expressiva, conclui-se que durante a Antiguidade Clássica, sobretudo representada nas pólis gregas Atena e Esparta e, posteriormente, por Roma, é que são observados os primeiros registros oficiais ocidentais. 
Esparta, de tradição bélica e esportiva, tinha na boa compleição física do indivíduo necessidade fundante para o sustento de seu poderio. Conforme Plutarco (1985), logo ao nascer os bebês deviam ser apresentados a uma junta de anciãos que, após inspeção detalhada poderia sentenciar, no caso de julgar o indivíduo frágil ou com características que denotassem deficiência, o abandono da criança ou arremesso do Monte Taigeto. Em Vidas Paralelas - Volume I - XVI, p. 1, o fato é assim registrado:

[...] depois que a criança nascia, o pai não mais era dono dela para educá-la à vontade, mas a levava para certo lugar a ele deputado que se chamava Lesche, onde os mais antigos de sua linhagem residiam. Visitavam eles a criança e, se a achavam bela, bem formada de membros e robusta, ordenavam fosse educada, destinando-Ihe nove mil partes das heranças para sua educação; mas, se lhes parecia feia, disforme ou franzina, mandavam atirá-la num precipício [...] (Plutarco, 1985, p. 01).

Atenas como Esparta possuía tradição militar, entrentanto, o maior destaque advinha de sua política, das leis e das artes desenvolvidas, exibindo também preocupações em relação à pessoa com deficiência, porém, em uma perspectiva divergente, que já previa o auxílio à sobrevivência de tal sujeito. Podese comprovar essa afirmação no seguinte trecho da fala do filósofo Aristóteles:

Existe, de fato, uma lei que estabelece que todo ateniense cujos bens não ultrapassem três "minás" e cujo corpo esteja mutilado ao ponto de não lhe permitir qualquer trabalho, seja examinado pelo Conselho e que seja concedido a cada um deles, a expensas do Estado, dois óbulos por dia para sua alimentação. E existe um tesoureiro dos deficientes, designado para tal. ("Constitution d'Athène", de Aristóteles - fragmentos).

Aristóteles anuncia a subvenção pública àquele incapaz de sustentar-se, no entanto, tal apoio financeiro destinava-se ao cidadão ateniense $e^{\mathrm{iii}}$, - o cidadão homem -, proprietário de terras, logo, de direitos políticos, excluindo de seu gozo, escravos, mulheres, artesãos e outros indivíduos livres, porém não atenienses.

Para o filósofo, o conceito de cidadão era adstrito aos homens livres. É interessante notar que Aristóteles estava preocupado em fundamentar um corpo ético que legitimasse as ações dos sujeitos. Isso explica seus conceitos de justiça e virtude presentes constantemente em seu pensamento contido em obras como, por exemplo, a Ética a Nicômaco, em que a felicidade é o fim último das ações humanas e que a justiça se encontra entre o excesso e a ausência, ou seja, na mediania, na virtude (Aristóteles, 2001).

Quanto aos cidadãos atenienses com deficiência, número significativo desses advinha de ferimentos durante as guerras, muito comuns nesse período, havendo ainda mutilações por castigos, nos casos de criminosos e escravos, acidentes de trabalho e doenças congênitas, estas em número reduzido em virtude do abandono, mortalidade e sacrifícios de bebês recém-nascidos por não serem considerados aptos aos ideais estéticos concebidos pela sociedade ateniense. 
A sociedade ateniense possuía um grau elevado de eugenia, predominando a predileção pelo homem perfeito. Platão, em $A$ República, descreve esse desejo pela perfeição:

\begin{abstract}
(...) Pais e filhos não terão outra preocupação do que a comunidade e formarão como que uma grande família, em lugar de famílias isoladas e fechadas em si mesmas. Os casamentos serão instituídos com vistas unicamente ao bem da cidade: serão celebrados os melhores casamentos para se obter a melhor descendência possível (Platão, 1996, p. 33-34).
\end{abstract}

Da decadência do poderio grego, ascende-se um novo império ainda maior. O império romano tinha como uma de suas características de domínio a apropriação ou incorporação de elementos culturais dos povos dominados, preservando conceitos, crenças, costumes e cultura dos subjugados. No caso da cultura dos gregos e sua influência na cultura romana, conforme Cícero (106 a.C. - 43 a.C.), aquela foi a maior provedora na formação intelectual do romano uma vez que as virtudes políticas e governamentais eram de exclusividade romana.

Ao contrário da concepção grega, que tinha a educação como responsabilidade do Estado, em Roma a responsabilidade educativa primária era do pater famílias, o homem romano que detinha poder absoluto e legal sobre esposa, filhos e seus escravos. Segundo a lei das Doze Tábuas, até o século V a.C., competia ao pater a educação inicial do filho sobre as letras, a oratória e as leis romanas e até mesmo a decisão entre a vida ou morte de seus filhos. A necessidade social atribuída ao Partus Prodigiosi ou "bom nascimento" do cidadão romano era premente para a sociedade romana, de modo que observa seu registro nas XII tábuas do Direito Romano. Na IV tábua fica sancionado o dever de, ao constatar-se deformidade na criança, o seu sacrifício. Ou seja, o pai deveria imediatamente matar o filho "monstruoso" e "contrário à forma do gênero humano", tão logo nascesse.

A incorporação de elementos da cultura grega, sobretudo na formação de cidadãos fortes, belos e hábeis nas artes de governar e guerrear, possivelmente influenciou os conceitos romanos sobre as pessoas com deficiência e suas tratativas. Tomando o exemplo de Esparta, há similitudes entre os povos no campo militar, contudo, o assassínio de bebês vistos como "anormais iv" não deve ser considerado uma exclusividade, sendo prática de outros povos e defendida por expoentes da filosofia ocidental. Platão (428 a 348 a.C.), em " $A$ República", tendo como ideal a formação do rei filósofo, assim expõe a questão:

[...] estabelecerás em nossa cidade médicos e juízes tais como os descrevemos, para tratarem os cidadãos que são bem constituídos de corpo e alma; quanto aos outros, deixaremos morrer os que têm o corpo enfermiço; os que têm a alma perversa por natureza e incorrigível serão condenados à morte (Platão, 2001, p. 137).

A não assistência, a marginalização e o desprezo foram condições fatídicas àqueles que, com deficiência, escapassem da imposição do partus prodigiosi. A esses ainda restava a continuação da luta pela sobrevivência, restando-Ihes conseguir, por meio da caridade, da esmola, da prostituição ou 
enquanto espécime bizarro para apresentação, ridicularização e divertimento da nobreza durante eventos sociais, sua subsistência.

O declínio do império romano no século IV d.C trouxe consigo a suplantação do politeísmo e a ascensão do cristianismo. A ideia de um Deus único, a promessa de um céu para quem não necessariamente pertencia a realeza, exigindo apenas a prática da caridade e o amor ao próximo, em pouco tempo ganhou adeptos das classes menos favorecidas, contudo, inicialmente houve grande resistência por parte das elites, gerando perseguição e morte dos primeiros cristãos. Tal situação, porém, começa a sofrer alteração e adesão por significativa parcela dos romanos, sobretudo por volta de 313 d.C. quando o então imperador Constantino sanciona o Édito de Milão, autorizando a liberdade de culto.

\section{A ldade Média e o cristão incômodo}

$\mathrm{O}$ período compreendido entre os séculos $\mathrm{V}$ e $\mathrm{XV}$, comumente denominado Idade Média, exibe singularidades como o feudalismo, o nascimento dos burgos, do arado, a ampliação da agricultura e estocagem, o surgimento da escolástica e de universidades ocidentais. A igreja detém forte poder político e do conhecimento, uma vez que a educação desenvolvia-se quase exclusivamente nos monastérios e/ou por meio do clero. Assim, ideais formativos da antiguidade clássica como a paideia, o ideal de formação do cidadão grego, junto com suas produções filosóficas e artísticas curvaram aos ditames da cultura cristã da época.

A formação intelectual era restrita a pequena parte da população composta por nobres e postulantes a cargos religiosos, dessa forma, não foram encontrados registros que vislumbrem uma preocupação formativa para a pessoa com deficiência. Contudo, por meio da firmação do monoteísmo cristão de abrangência global, às pessoas com deficiência o cristianismo instituiu que os mesmos eram também filhos de Deus, detentores de alma, logo, merecedores do direito à vida. Para Cambi (1999):

O advento do cristianismo operou uma profunda revolução cultural no mundo antigo, talvez a mais profunda que o mundo ocidental tenha conhecido na sua história. Uma revolução da mentalidade, antes mesmo que da cultura e das instituições sociais e, depois, políticas também" (vindo a) modelar toda a visão da sociedade e também os comportamentos coletivos [...] (CAMBI, 1999, p. 121).

Dessa forma, a revolução da mentalidade identificada por Cambi, condicionada pelas transformações das condições de existência já esposadas apesar do grande impacto na sociedade em geral, às pessoas com deficiência ou o cristão incômodo, teve efeito inicial apenas lenitivo, uma vez que a contradição é posta pela própria religião e seu Tribunal Eclesiástico, designado para julgar crimes contra a fé cristã, e popularmente conhecido pelo nome de Inquisição, responsável pela morte de muitas pessoas com deficiência, como se verá a seguir. 


\section{O demônio e a deficiência}

A pessoa com deficiência, por meio da ascensão da fé cristã durante a Idade Média, passou a ser considerada também "filha de Deus" e detentora de alma. A nova visão foi singular ao prevenir situações como o parricídio de outrora, no entanto, o preventivo se mostrou limitado em um período no qual fé e ciência tinham divergências e forças desproporcionais, uma vez que: enquanto uma reinava quase absoluta, outra dava os primeiros passos de desenvolvimento, sempre vigiados por uma sociedade eivada de misticismo e medo. Com Tomás de Aquino, a filosofia ganha um novo patamar, dialogando com a teologia, à qual esteve historicamente subordinada e, com René Descartes, o pensamento racional e metódico se destaca, contribuindo para o nascimento da ciência modernav.

No referido período, a inexistência de investigações sobre as pessoas com deficiência, no campo científico, e o desconhecimento e fanatismo religioso de parcela significativa da sociedade, que confundia ciência com bruxaria, proporcionaram, por diversas vezes, que pessoas com deficiência fossem consideradas bruxas ou "endemoniadas". Para Pessotti (1984), a pessoa com deficiência no século V:

[...] era visto como portador de desígnios especiais de Deus ou como presa de entidades malignas às quais "obviamente" serviria através de atos bizarros como os das bruxas. Dada a credulidade da população rural e seu fanatismo clerical, não surpreende que entre as cem mil pessoas queimadas por bruxaria, só na Alemanha do século XVII, estivessem incluídos centenas de dementes e amentes ou deficiente mentais (PESSOTTI, 1984, p. 9).

A citação de Pessotti, já durante o século XVII ou dois séculos após o término consensual da Idade Média, embora se refira à pessoa com deficiência intelectual, possibilita expansão hipotética sobre condição análoga de tratamento a pessoas com outras deficiências. Dessa forma, conclui-se que pessoas com epilepsia, paralisia cerebral ou outra condição cuja manifestação destoasse muito do normotípico, também estaria sentenciada à morte, pois eventos hoje considerados comuns, à época, já supunham obra demoníaca. Para Byington (1997), no prefácio da obra Malleus Malleficarum ou Martelo das Feiticeiras ${ }^{\text {vi: }}$

Uma pessoa de conduta diferente, uma briga entre vizinhos, uma vaca que dá mais ou menos leite, uma criança que adoece, uma tempestade ou a diminuição da potência sexual, qualquer ocorrência pode ser atribuída à bruxaria (Byington,1997, p. 20).

Havia também a estreita e, por vezes oportuna, relação entre os julgamentos de pessoas consideradas endemoniadas e a espoliação de seus bens. Por meio da De praerogativa regis, séc. XIV, conforme Pollock e Maitland (1898), é afirmado o direito de posse de terra herdada ou proveniente de renda deste, sendo mantida por familiares ou outros tutores indicados por ordem da coroa. Por lei, as posses deveriam ser preservadas até que o lunático - termo utilizado na época- recobrasse suas plenas faculdades, entretanto, neste ínterim, caso esse não fosse considerado possuído ou algo do tipo, poderia facilmente ser morto via inquisição, passando suas posses para um familiar ou tutor. 
Lamentavelmente, ao sujeito estereotipado, além de suas características orgânicas, ter posses poderia ser um infortúnio capaz de tirar-lhe a vida, já que demônio e deficiência comumente tornavam-se sinônimos em prol de terceiros.

A esteira da história prossegue e o feudalismo exibe os últimos suspiros no século XV. No campo econômico-político, a burguesia ganha força com o comércio mercantil e as grandes navegações em detrimento da aristocracia feudal; no teológico, o poderio e conduta da igreja são questionados, gerando a cisão da mesma e o surgimento do protestantismo e calvinismo; ocorrem os primeiros estudos ocidentais voltados para a pessoa com deficiência, apresentados por Teofrasto Paracelso (1493-1541) e Jerônimo Cardano (15011576) que, embora com produções ainda bastantes carregadas do misticismo medievo, promovem o pensamento protocientífico culminando, posteriormente, com ideais de Renascimento e lluminismo.

A busca da reflexão com base na razão antropocêntrica observada com maior ênfase no final do século XVI, com o Renascimento e a revalorização do legado da civilização grega, gerou condições para o movimento lluminista a partir do século XVIII. Do período iluminista têm-se o fortalecimento científico, das artes e das leis, cujas bases são o empirismo e a valorização da natureza humana como motor do desenvolvimento do mundo, em distintas matizes dentro daquilo que Elias (1994) denominou arcabouço básico de funções interdependentes.

Assim, Locke (1690) com o empirismo e liberalismo político; Montesquieu (1762) e a crítica ao absolutismo e defesa do governo tripartite; Voltaire (1768) e sua análise denunciativa ante o clero e os impostos; Rousseau (1762) e a educação vinculada à ideia de liberdade e natureza e Adam Smith (1776) com o liberalismo econômico; dentre outros, alçam o pensamento liberal, a discussão científica, a educação e a compreensão social a patamares inéditos até então.

A valorização científica da empiria suscitou pesquisas favoráveis sobre a capacidade das pessoas com deficiência de aprender, tendo, além de alma, agora a condição de exercitar a razão, ainda que em regime de clausura. John Locke, considerado o pai do empirismo, publica em 1689 o livro "Ensaio sobre o entendimento humano", no qual sustenta a teoria de valorização das experiências na formação do indivíduo que ao nascer é como uma Tábula Rasa. Para Locke, pertencente à classe liberal burguesa emergente, empirismo era também um posicionamento revolucionário que insurgia contra a teocracia dos reis que entendiam, dentro da noção do inatismo platônico, que eram herdeiros diretos de Deus. Para o autor: "Não se pode afirmar que qualquer proposição está na mente sem ser jamais conhecida e que jamais se tem disso consciência (LOCKE, p.36, 1999)." Observa-se que à época, o capitalismo, ainda sob a forma mercantil, precisava expandir-se, e encontrava nas tradições do antigo regime absolutista feudal verdadeiros obstáculos para sua consolidação.

O pensamento de Locke contribuiu para que Denis Diderot, em 1749 escrevesse "Carta sobre os cegos para uso daqueles que enxergam", enaltecendo a capacidade dos cegos aprenderem por meio das sensações e sentidos. As produções de Locke e Diderot, possivelmente contribuíram para que em 1784, Valentin Hauy fundasse o Instituto Nacional dos Jovens Cegos, em Paris, anunciando o pioneirismo institucional na proposição da formação da pessoa com deficiência.

O século XVIII ainda vivenciou dois eventos que reverberaram de maneira transcontinental: a Revolução Francesa e a Revolução industrial, tendo como pano de fundo o liberalismo, a laicização e a nova conformação social capitalista. 
advento do capitalismo oportuniza transformações de amplo espectro, demarcando a existência de classes distintas: burguesia e proletariado. A burguesia, outrora revolucionária, agora é composta por grandes industriais detentores dos meios de produção, e os operários, muitos dos quais, antigos camponeses, não possuíam terras, tendo para sua sobrevivência apenas a oferta de sua força de trabalho.

De um lado as condições insalubres das fábricas, as longas jornadas de até 18 horas de trabalho, os baixos salários e, em consequência, as revoltas da classe explorada; de outro a busca do excedente de produção e do lucro, a instrução para o correto manuseio dos equipamentos a vapor e a necessidade da imposição de controle da burguesia sobre as revoltas operárias, foram as condições impositivas para a ampliação do processo de alfabetização e do surgimento de escolas, o que ratifica a assertiva de Manacorda (2004, p. 248) de que "Escolas e fábricas nascem juntas."

\section{O Cenário Brasileiro}

O Brasil surge durante os albores do capitalismo em sua fase mercantilista, marcada por grandes campanhas de navegação e o entendimento em que o poderio estatal se baseava na quantidade de terras e metais preciosos que detinha. O processo de independência do Brasil ocorreu em 1882, pouco tempo após as grandes Revoluções ocorridas durante o século XVIII, Política na França e Industrial na Inglaterra, sendo, naquele contexto, um país escravocrata, de modelo agrário-exportador e de maioria populacional analfabeta.

Dois anos após a declaração de independência, anuncia-se a primeira Constituição em março de 1824. Para Bonavides (2000, p.167), a carta ampliava e centralizava os poderes do Imperador por meio do poder moderador que, da maneira como fora utilizado: "[...] era a programação deliberada da ditadura porquanto contrariava a regra substantiva de Montesquieu da divisão e limitação de poderes". A primeira Constituição assegurava em seu artigo 179, inciso XXII “ A Instrucção primaria, e gratuita a todos os Cidadãos", no entanto, a cidadania se restringia a homens, excluindo mulheres e escravos, e sobre as pessoas com deficiência, lembra-se apenas no artigo $8^{\circ}$, inciso I, como um dos quesitos para a perda dos direitos de cidadania a "incapacidade physica ou moral" (BRASIL, 1824).

Sobre a preocupação formativa das pessoas com deficiência, essa é oficializada em 1854, quando o imperador Dom Pedro II, por meio do decreto 1428, cria o Imperial Instituto de Meninos Cegos, atualmente denominado Instituto Benjamin Constant (IBC).

Idealizado pelo professor José Alvares de Azevedo que fora aluno do Instituto de Meninos Cegos de Paris e que, ao retornar para o Brasil, em 1850, passou a lecionar para a garota cega Adélia Sigaud, filha do médico da corte Dr. Francisco Xavier Sigaud. Os resultados prósperos na aprendizagem e alfabetização de Adelia por meio do Braille causaram entusiasmo ao pai da garota, que oportunizou audiência do professor com o imperador, fato que culminou anos depois com a fundação do Institutovii.

Após a fundação do Imperial Instituto de Meninos Cegos é criado com a Lei 939 de 1857 e através dos esforços do professor francês surdo Edgar Houet, o 
Instituto de Surdos-Mudos, hoje denominado Instituto Nacional de Educação de Surdos (INES). Ambos os institutos foram as primeiras iniciativas voltadas para a escolarização das pessoas com deficiência, constituindo-se como centros de referência em toda a América Latina. Até o surgimento deles, às pessoas com deficiência restava o atendimento de viés médico ou caritativo em asilos distribuídos pela corte e em algumas províncias de maior desenvolvimento, mas com nenhum interesse formativo. Assim, embora atendessem poucas dezenas de estudantes em seus primeiros anos, IBC e INES foram basilares para o surgimento de outras instituições em um país de educação ainda restrita, conforme ressalta Jannuzzi (2006):

\begin{abstract}
A educação popular, e muito menos a dos deficientes, não era motivo de preocupação. Na sociedade ainda pouco urbanizada, apoiada no setor rural, primitivamente aparelhado, provavelmente poucos eram considerados deficientes; havia lugar, havia alguma tarefa que muitos deles executassem. A população era iletrada na sua maior parte, as escolas eram escassas, como já salientado, e dado que só recorriam a ela as camadas sociais alta e média, a escola não funcionou pelo crivo, como elemento de patenteação de deficiências (Jannuzzi, 2006, p. 16).
\end{abstract}

Do exposto infere-se que a educação formal ou escolarizada era praticamente inexistente naquele tempo, restringindo-se a pequena parcela da população. Aos demais restava o aprendizado adquirido no dia a dia por meio dos familiares e vinculado diretamente ao trabalho; assim IBC e INES quando de sua criação, apesar de seu singular vanguardismo em relação à educação escolarizada da pessoa com deficiência, apresentavam em sua estrutura didática forte apenso ao trabalho com disciplinas de práticas manuais como encadernação, conserto de pianos e confecção de vassouras (Moises, 2019). Da vinculação dos Institutos fica o entendimento da necessidade de tornar o indivíduo com deficiência capaz de ser produtivo e subsistente ante o capitalismo que aflorava.

No ano de 1888 é decretada a abolição da escravatura ${ }^{\text {viii }}$ e no ano seguinte, em 15 de novembro de 1889, é proclamada a república e em 1891 promulgada a nova constituição. O fim da escravidão trouxe a necessidade de outros trabalhadores que agora deveriam ser pagos, culminando com a vinda de grande número de imigrantes de diferentes nacionalidades para o Brasil. Conforme Figueira (2008, p. 69), "Entre 1901 e 1920, mais de um milhão de estrangeiros chegaram ao país - $60 \%$ deles foram para as zonas rurais e urbanas de São Paulo, atrás do sonho verde do café".

Entre 1914 e 1918, o mundo passa pela Primeira Guerra Mundial com efeitos sentidos em escala global. Dos soldados que retornaram para seus países, muitos apresentaram sequelas de combate, tornando-se pessoas com deficiência, o que forçou o poder público a tomar decisões e providências no âmbito médico, assistencial e formativo. Passado a guerra, o cenário no Brasil é de crescente industrialização, contudo, ainda inferior à cultura agrária e à sua política do "Café com Leite". A relativa autonomia adquirida pelos estados no cenário pósproclamação da República permitiu que esses começassem a organizar seu ensino primário que se formou com a contribuição de diferentes profissionais e assim: 
Profissionais diversos como médicos, psicólogos, professores, vão atuando na área, estruturando no fim dos anos de 1920 a base de associações profissionais que, de maneira ambígua e imprecisa, foram criando um campo de reflexão à procura de um espaço efetivo para a concretização de sua ação pedagógica (Jannuzzi, 2006, p. 24).

Na primeira metade da década de 1930, com o contingente populacional em crescimento acelerado, tornou-se necessário o investimento em hospitais para o atendimento populacional, uma vez que assim como ocorrera durante a revolução industrial na Inglaterra entre os séculos XVIII e XIX, a modernização da produção brasileira foi a responsável por milhares de acidentes que causaram deficiências, quando não a morte a inúmeros operários.

Movimentos sociais e da classe operária se organizam, há o aumento da escolarização e a Constituição de 1934 fixa direitos trabalhistas e o voto das mulheres; o entendimento sobre o direito e capacidade da educação da pessoa com deficiência amplia-se. A educadora Helena Antipoff organiza cursos de formação voltados à psicologia e educação do estudante com deficiência em diferentes estados brasileiros fundando, em 1932, a sociedade Pestalozzi de Minas Gerais ${ }^{\mathrm{ix}}$.

A década de 1930 também traz consigo o movimento higienista de forte inspiração médica e que defendia a proposição de uma educação eugênica para gênese de uma nação forte e saudável, e no âmbito escolar, o escolanovismo propõe uma educação laica e gratuita, expressa no documento Manifestos dos Pioneiros da Educação em 1932. Tanto higienismo quanto escolanovismo apresentaram impactos históricos ainda observados na educação das pessoas com deficiência ao tentar propor um entendimento normativo, no qual essa deveria ser educada dentro dos ditames da normalidade e do determinismo social. Desta forma, compreendem que a educação:

[...] deixa de constituir um privilégio determinado pela condição econômica e social do indivíduo, para assumir um "caráter biológico", [...] até onde o permitam as suas aptidões naturais, [...] preparando-se para formar "a hierarquia democrática" pela "hierarquia das capacidades" (Manifesto, 2006, p. 191).

Apesar do mérito de propor a democratização do ensino primário, o foco no rendimento biológico para uma hierarquia supostamente democrática institui, paradoxalmente, um distanciamento meritocrático que reforça a marginalização dos menos capazes, dentre estes as pessoas com deficiência. Tais indivíduos, embora não mais lançados do Monte Taigeto ou queimados em fogueiras como outrora, são inseridos em uma corrida desigual, onde o referencial é a convenção social que define o que é normal ou anormal. Em outras palavras, não há uma preocupação em atribuir tratamento igual para iguais e desigual para desiguais na proporção das limitações dessas desigualdades, conforme Aristóteles (2001).

O final da década de 1930 ainda presencia a instituição do Estado Novo com forte inspiração fascista, retirando direitos políticos e o direito à oposição democrática. Do Estado Novo pouco se discute sobre as pessoas com deficiência, sabe-se que o Instituto Benjamin Constant fechara, no período, para reforma, mantendo apenas sua imprensa; não se esclarece o destino daqueles que viviam 
no instituto. Antecedendo à Segunda Guerra em dois anos (1937), o Estado Novo se encerra um ano após o encerramento desta, em 1946 com a consequente promulgação de uma nova Constituição.

A Segunda Guerra, com seus resultados destrutivos e a morte de milhões de pessoas, impôs uma reflexão forçada às nações de todo o mundo. Tal reflexão culminou com a criação da Organização das Nações Unidas (ONU) cujos signatários:

[...] resolvidos a preservar as gerações vindouras do flagelo da guerra, que por duas vezes, no espaço da nossa vida, trouxe sofrimentos indizíveis à humanidade, e a reafirmar a fé nos direitos fundamentais do homem, na dignidade e no valor do ser humano, na igualdade de direito dos homens e das mulheres, [...]. (ONU, 1945).

O documento influenciou documentos por todo o mundo, trazendo à baila a preocupação com a defesa de minorias e vulneráveis. No Brasil, no ano seguinte à criação da ONU, tem-se a nova Constituição (1946) dentro de uma concepção democrática que determinava a educação como direito assegurado a todos (art. 166) e de acordo com Pletsch (2014, p. 73), o período ensejou "[...] com base nos preceitos do pensamento evolucionista presente na ciência moderna, em consonância com o discurso liberal, foram criadas as primeiras classes especiais sob a supervisão da inspeção sanitária para separar os 'normais' dos 'anormais' " (aspas da autora).

De origem europeia e trazida para o Brasil por Helena Antipoff, às classes especiais implicavam a noção de homogeneização à luz do modelo taylorista com o nivelamento das capacidades intelectuais dos estudantes com base na avaliação de inteligência e vocabulário, (ANTIPOFF,1932 apud BORGES, 2015). Ainda apartadas da formação junto às pessoas ditas normais, as classes especiais apesar da segregação dentro do lócus escolar, apresentam o mérito de ensaio da inserção do aludido estudante dentro do processo de escolarização formal.

Durante a década de 1950, o debate sobre o direito de aprender das pessoas com deficiência ganha notoriedade por meio de fóruns, encontros de especialistas e campanhas. Em 1957 merece registro a campanha nacional de educação do surdo, é nesse período também que no Rio de Janeiro, conforme observa Pletsch (2014), é fundada em 1954 a Associação de Pais e Amigos dos Excepcionais (APAE), atualmente com mais de 2200 unidades espalhadas por todo o país. Três anos seguintes, já durante os anos sessenta, ocorre campanha nacional do deficiente mental ${ }^{\times}(1960)$.

Por meio da Lei de Diretrizes e Bases da Educação (LDB no 4024/1961), a pessoa com deficiência é citada, agora não como condição excludente de cidadania, mas como observado em documentos nacionais anteriores, detentora do direito à educação escolarizada devendo ser oferecida "no que for possível (...) no sistema geral de educação" com vistas à integração na comunidade (BRASIL, 1961).

O condicionante "no que for possível", presente no artigo 88 da referida lei, prejudicou o efetivo ingresso e permanência de estudantes com deficiência nas classes comuns e, associado ao artigo 89, que previa o fomento de instituições de caráter privado por meio do poder público, ocasionou que a maioria dos estudantes permanecessem nas instituições até a década de 1990. 
De abril de 1964 a março de 1985 o país vive seu período mais sombrio: a ditadura militar torturou, matou e levou ao exílio milhares de brasileiros, muitos dos quais intelectuais de diversas áreas. Como modelo replicante dos ditames norteamericanos e com vistas à formação de um capital humano forte e preparado para a modernização via capital e para a guerra, à educação da pessoa com deficiência ficou destacado para o período a transição do modelo médico para o educacional de ensino dentro da educação especial conforme (PLETSCH, 2014) e a criação do Centro Nacional de Educação Especial (CENESP) em 1973, tendo por finalidade:

[...] planejar, coordenar e promover o desenvolvimento da Educação Especial no período pré-escolar, nos ensinos de $1^{\circ}$ e $2^{\circ}$ graus, superior e supletivo, para os deficientes da visão, da audição, mentais, físicos portadores de deficiência múltiplas, educandos com problemas de conduta e os superdotados, visando à sua participação progressiva na comunidade, obedecendo aos princípios doutrinários, políticos e científicos que orientam a Educação Especial (MAZZOTTA, 2003, p.57).

Com o fim da ditadura em 1985, o país tem crescimento científico, com o retorno de intelectuais que, exilados, realizaram pesquisas em nível de mestrado e doutorado em diferentes países. O desenvolvimento irá influenciar diferentes áreas e na educação promoverá o salto de uma condição de integração, isto é, onde o indivíduo deveria preparar-se para participar da "sociedade dos normais" para a inclusão, dentro de uma proposta dialética e de alteridade por meio da convivência das diferenças em ambientes de comum direito a todos ${ }^{\mathrm{xi}}$.

Dentro do limite do recorte temporal proposto, para-se em 1985, início do período democrático brasileiro, todavia, o avanço do tempo exigiria, citar ainda a constituição cidadã de 1988, o Estatuto da Criança e do Adolescente, a nova LDB 9394/1996, e o Estatuto da Pessoa com deficiência (lei 13146/2008) dentre outros documentos, bem como as renitentes investidas de alas liberais do governo em inviabilizar direitos das pessoas com deficiência, como a acessibilidade, a educação o ingresso ao trabalho dentre outros. Para fins didáticos, os principais eventos do recorte temporal investigado, considerando o objeto e a perspectiva de análise apresentada nesse artigo, são assim resumidos no esquema temporal a seguir: 
Esquema 1: resumo das principais datas histórica do recorte temporal investigado

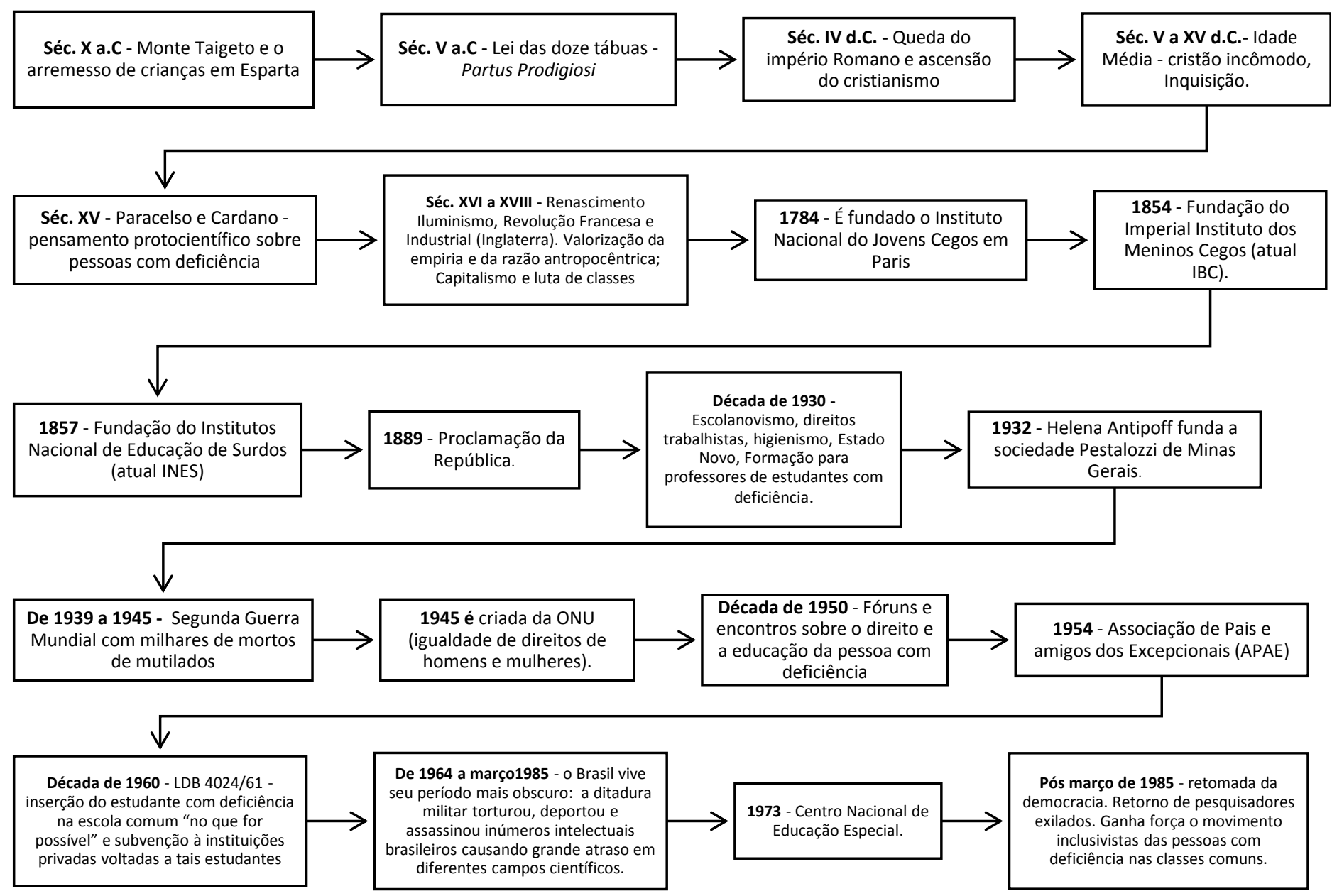

Fonte: Elaboração dos autores.

\section{Considerações finais}

A humanidade passou por diferentes períodos civilizatórios, cuja formação cultural com seus conceitos e tratativas foram frutos da condição de desenvolvimento do modo de produção vigente. Em relação às pessoas com deficiência ficou constatado que a história relegou, por longo período o tratamento marginalizante com o extermínio, abandono, exploração ou cárcere.

$\mathrm{O}$ advento do capitalismo, o estabelecimento do antagonismo de classe entre os detentores dos meios de produção (burguesia) e aqueles que possuíam apenas a força de trabalho (operários) deflagraram movimentos de atrito social com a organização de minorias na luta por melhores condições de trabalho, de educação, de saúde, enfim, condições dignas de vida.

A análise esposada no presente artigo, dentro do recorte temporal que no âmbito geral cinge-se das primeiras manifestações primitivas, e no nacional,

History of Education in Latin America - HistELA, v. 3, e20780, 2020, p. 14 de 17 
encerra-se com a retomada democrática do Brasil (1985) e promulgação da Constituição Democrática de 1988, permite o entendimento que a história da pessoa com deficiência desenvolveu-se dentro de uma temporalidade histórica paralela à da pessoa considerada normal, cabendo como exigência primária à pessoa com deficiência provar-se, antes de tudo, humano e produtivo, para assim poder pleitear o desfrute das riquezas socialmente produzidas.

No Brasil, quase dois séculos após as primeiras iniciativas de escolarização da pessoa com deficiência, têm-se que a inclusão maciça de tais estudantes nas escolas, deu-se efetivamente somente a partir da década de 1990, havendo, portanto, muito ainda por se fazer com relação a sua permanência, êxito e garantia da aprendizagem.

\section{Referências}

Aristóteles. (2001). Política. Rio de Janeiro: Martin Claret.

Aristóteles. (2001). Ética a Nicômaco. São Paulo - SP: Martin Claret.

Bonavides, P. (2000). A evolução constitucional do Brasil. Estudos avançados, 14(40), 155-176.

Borges, A. A. P. (2015). As classes especiais e Helena Antipoff: uma contribuição à história da educação especial no Brasil. Revista Brasileira de Educação Especial, 21(3), 345-362.

Brasil. Resolução CNE/CEB 4/2009. Diário Oficial da União, Brasília, 5 de outubro de 2009, Seção 1, p. 17.

Brasil. Constituição Politica do Império do Brazil, de 25 de março de 1824.

Disponível em:

<https://legislacao.planalto.gov.br/legisla/legislacao.nsf/viwTodos/e964c0ab751ea 2 be032569fa0074210b?OpenDocument\&Highlight=1,\&AutoFramed>. Acessso em 17 de abril de 2020.

Brasil. Senado Federal. Lei de Diretrizes e Bases da Educação Nacional: $n^{\circ}$ 4024/61. Brasília: 1961. Disponível em:

http://presrepublica.jusbrasil.com.br/legislacao/129047/lei-de-diretrizes-e-basede1961-lei-4024-61. Acesso em: 20 de abril de 2020.

Cambi, F. (2002). História da pedagogia. Unesp.

Elias, N. (1994). A Sociedade dos Indiv'duos. Zahar.

Engels, F. (1932). Anti-duhring; filosofía, economía, política, socialismo (No. 04; HX276, E5.).

Figueira, E., No Silêncio, C. (2008). Uma introdução à Trajetória das Pessoas com Deficiência na História do Brasil-Giz Editora. São Paulo.

Jannuzzi, G. D. M. (2005). A educação do deficiente no Brasil: dos primórdios ao início do século XXI. Cadernos de Pesquisa, 35(124), 255-256.

Kramer, H. (1997). O martelo das feiticeiras. Editora Best Seller.

Locke, J., \& Aiex, A. (1999). Ensaio acerca do entendimento humano.

Manacorda, M. A. (2004). História da Educação: da antiguidade aos nossos dias.

7. Ed. São Paulo - SP, Cortez, 2004. 
MANIFESTO DOS PIONEIROS DA EDUCAÇÃO NOVA. Revista Histedbr online.

Campinas, n. especial. p. 188-204. 1932 - ago. 2006. Disponível em

$<$ <ttp://www.histedbr.fae.unicamp.br/doc1_22e.pdts. Acesso em 16 de abril de 2020.

Mazzotta, M. J. S. (2003). Educação especial no Brasil: história e políticas públicas. 4. ed. São Paulo: Cortez, 2003.

Moises, R. R. (2019). Ginástica e Educação Física no Instituto Benjamin Constant de 1930 a 1979: entre a conformação e a formação humanística da pessoa cega. Tese (doutorado em educação) - Universidade Federal de São Carlos, São Carlos, 2019. Disponível em:

<https://repositorio.ufscar.br/handle/ufscar/12661 >. Acesso em 30 de abril de 2020.

ORGANIZAÇÃO DAS NAÇÕES UNIDAS (ONU), A Carta das Nações Unidas, 1945. Disponível em <https://nacoesunidas.org/carta/>. Acesso em 18 de abril de 2020.

Pessotti, Isaías. (1984). Deficiência mental: Da Superstição a Ciência. São Paulo: Queiroz.

Platão. (2001). A República. Trad. Maria Helena da Rocha Pereira. Lisboa: Fundação Calouste Gulbenkian, 2001.

Platão. (1996). A República. Trad. Elza Moreira Marcelina. Brasilia: Universidade de Brasília, 1996.

Pletsch, M. D. (2014). Repensando a inclusão escolar: diretrizes políticas, práticas curriculares e deficiência intelectual. Rio de Janeiro: NAU; EDUR.

Plutarco. (1985). Vidas paralelas Vol. I: Teseo, Rómulo, Licurgo, Numa. [Introducción traducción y notas de Aurelio Pérez]. Madrid: Gredos.

Pollock, F. Maitland, F. W. (1898). The History of English Law Before the Time of Edward I. 2d ed., Cambridge: Cambridge University Press. Disponível em:<https://archive.org/details/historyofenglish00polluoft/page/n3/mode/2up/searc $h / v e r y>$. Acesso em 31 de março de 2020.

Silva, O. M. (1987). A epopeia ignorada - A História da Pessoa Deficiente no Mundo de Ontem e de Hoje, São Paulo, Cedas.

Vigotski, L., S. (1998). Pensamento e linguagem. São Paulo: Martins Fonte.

Weiszflog, W. (2020). Dicionário Michaelis da língua portuguesa [on-line]. São Paulo: Melhoramentos. Disponível em:

$<$ http://michaelis.uol.com.br/busca? $r=0 \& f=0 \& t=0 \&$ palavra $=$ conceito $>$. Acesso em 28 de abril de 2020.

\section{Notas}

\footnotetext{
i Com a finalidade de se evitar entendimentos generalistas sobre o capitalismo ratificamos que o mesmo é, até o momento, o modo de produção que oportunizou maior estágio de desenvolvimento de tecnologias e de produção de riquezas socialmente construídas, todavia, é também o que apresenta maiores contradições como a concentração das produções e excedentes nas mãos de poucos eleitos em detrimento de uma maioria que, não dona dos meios de produção, tem apenas sua força de trabalho para garantia de sua subsistência e dos seus.
} 
ii Entendemos como minorias vinculadas aquelas que no período tinham ligação direta com a classe trabalhadora, por exemplo os filhos de operários que, para que esses pudessem trabalhar necessitavam de escolas.

iii Para Silva (1987), o número de indivíduos com deficiência durante a Antiguidade Clássica mantidos pelo governo ateniense chegou ao total de 20.000 .

iv O termo hoje encontra no campo acadêmico repulsa e censura da qual somos signatários, todavia, ressaltamos que era termo comum e usual no período em questão e utilizado até recentemente,

${ }^{\vee}$ Outros pensadores de diversos também contribuíram com essa transição epistemológica como Guilherme de Ockham, David Hume entre outros.

vi Obra originalmente datada de 1486 por Heinrich Kramer e James Sprenger (1486) e que junto com seu o predecessor "Directorium Inquisitorium", de Nicolás Aymerich (1376), apresentavam as diretrizes para investigação, julgamento, sentença e execução de pessoas consideradas endemoniadas.

vii Infelizmente José Alvares de Azevedo faleceu há poucos meses da criação do instituto.

viii A escravidão que no Brasil durou mais de três séculos, nosso país sustenta o vexatório título de última nação da américa latina a abolir a escravidão. A escravidão foi a responsável pela morte e mutilação de milhares de escravos por meio das péssimas condições de trabalho e os comuns castigos corporais como observa Figueira (2008). In: Caminhando em Silêncio - Uma introdução à trajetória das pessoas com deficiência na história do Brasil., São Paulo: Giz Editora, 2008.

${ }^{i x}$ Conforme Fenapestalozzi (2016), o primeiro Instituto Pestalozzi foi criado em canoas RS no ano de 1926. Disponível em:< http://www.fenapestalozzi.org.br/wp-content/uploads/2014/05/BoletimEspecial-Congresso.pdf>. Acesso em 18 de abril de 2020.

x Um dos termos utilizados para denominar o indivíduo com deficiência intelectual na época.

${ }^{x i}$ Dentre as minorias, as pessoas com deficiência e familiares passaram a se aparelhar e órgãos representativos cuja luta em diferentes frentes proporcionou mudanças de âmbito legal e de leis assegurando condições mais dignas visando a garantia de direitos dentre os quais à formação escolarizada. 